\title{
The Comparision of Antioxidant and Reactive Oxygen Scavenging Capacities of Ethanol, Methanol and Aqueous Extracts of Various Natural Leafs
}

\author{
Hatice BAŞ ${ }^{\mathbf{a}}$, Dilek PANDIR ${ }^{\mathrm{a}}$

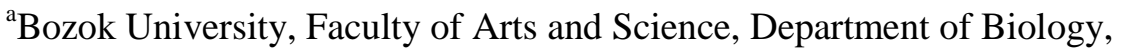 \\ Divanliyolu/Yozgat, Turkey
}

\begin{abstract}
Leafs have contain wide antioxidant range which may provide prevention against radical oxygen species. The aim of this work was to measure the antioxidant capacity of 15 commercially available leaf extracts (ethanol, methanol, water) using ferric reducing antioxidant power (FRAP) assay and trolox equivalent antioxidant capacity (TEAC) assay. Also we evaluated total phenolic and monomeric anthocyanin contents, hydroxyl radical and superoxide scavenging capacities, too. It was obtained that, although water, ethanol and methanol extracts of $M$. communis had the highest antioxidant and reactive oxygen scavenging capacities. Also it had the highest total monomeric anthocyanin and phenolic contents. In addition, water, ethanol and methanol extracts of S. nigra was the least effective ones. It had the lowest total phenolic content, total monomeric anthocyanins, antioxidant and reactive oxygen scavenging capacities. For all parameters, values were in the order: Ethanol extract < Methanol extract < Water extract. It was concluded that extractions of some leafs possessed antioxidant and reactive oxygen scavenging capacities. Antioxidant and reactive oxygen scavenging capacities, total phenolic content, total monomeric anthocyanins of water extracts of leafs were higher than the extracts of ethanol and methanol. Further work will be carried out to find biologically active compounds of them.
\end{abstract}

Keywords: extracts; antioxidant; free radicals; FRAP; TEAC

\section{INTRODUCTION}

Reactive oxygen species (ROS) are perpetual formed in physiological process and many times overproduced, resulting in oxidative stress. To preserve their harmful effects to biological molecules such as proteins, DNA, lipids and other non-enzymatic and enzymatic components are serving in the antioxidant system [1-3]. As the significance of prooxidants, especially of ROS gains more identification in stress biology [4,5], it is of specific attention whether ROS scavenging capacities are reflected in total antioxidant capacity. In leaf extracts, we assessed superoxide neutralizing and hydroxyl radical scavenging capacities. These data were compared to FRAP and TEAC assay results and with leaf antioxidant amounts, for example phenolics and anthocyanins [6].

Antioxidants are able to quench the proliferation of peroxyl radical (ROO), hydroxyl radical ( $\mathrm{OH}$ ) and superoxide anion radical $\left(\mathrm{O}_{2}^{-}\right)$are generated both by external sources such as environmental pollution, UV radiation and aerobic metabolism [7] which are implicated in the pathology of different diseases $[8,9]$. Natural antioxidants, which found in vegetables and fruits have gotten increasing attention between the scientific community because studies have demostrated that continual consumption of natural antioxidants is related to a lower risk of cancer and cardiovascular disease $[10,11]$. The natural antioxidants' preventive effects in vegetables and fruits are interested in four main groups: phenolics, anthocyanins, vitamins, and carotenoids [12]. Vegetables and fruits can form a substantial source of antioxidants [13, 14]. The term herb mentions not only to gramineous plants, but also to the leafs, flowers, bark, fruits, seeds and roots [15]. Extracts of leafs are strong antioxidants, principal having to the presence of $(-)$ epigallocatechin, $(-)$ epicatechin, $(-)$ epicatechin gallate, $(-)$ epigallocatechin gallate and (+)catechin [16]. Tea polyphenols are natural antioxidants [17] and took in consideation to be liable for the anti-mutagenic and anti-carcinogenic properties of tea, alongside prevention role against diseases especially cancer and cardiovascular disorders [18-21].

Definition and mensuration of antioxidant properties, anthocyanin and phenolic contents of plants, are well defined [22-24]. Also, there are some studies which showed health adventages of the plants. 
However, studies and antioxidant properties of 15 leafs which were studied in this work are very limited.

The ferric reducing/antioxidant potential (FRAP) assay is an inexpensive and simple measurement that determines the levels of total antioxidants in a sample. It benefits the reducing antioxidant potentials to react with a ferric tripyridyltriazine $\left(\mathrm{Fe}^{\mathrm{III}}-\mathrm{TPTZ}\right)$ complex and generate ferrous tripyridyltriazine ( $\mathrm{Fe}^{\mathrm{II}}$-TPTZ) which is a colored form [25-27]. Values of FRAP are achieved by measuring the absorbance in test mixtures that involving ferrous ions in known concentration [25].

The trolox equivalent antioxidant capacity (TEAC) assay predicates on the $\mathrm{ABTS}^{+}$radical scavenging via the antioxidants of a sample. The $\mathrm{ABTS}^{+}$radical has a bluish-green colour [28]. If there are antioxidants in the reaction mixture, they hold the free radicals, and loss of colour was observed. Therefore a decrease in absorbance presents [29].

The assessment of the antioxidant capacity of foods discourses because it may supply a variation of data, such as quantitative contribution of antioxidant compounds, resistance to oxidation or the possible antioxidant capacity that they may available inside the body when ingested [30,31]. Studies on extracting of compounds from plants and examining the free radical scavenging capacities of the drugs procure a great quantity of antioxidants [32]. Countless works have been done to determine the antioxidant capacity of foods. Thus, the purpose of this work were to quantify of the antioxidant and reactive oxygen scavenging capacities of 15 tea extracts. The talent of extracts of leafs to withstand oxidative stress induced damages and free radical scavenging ability were specified as decreasing ability by FRAP and TEAC assays [33]. The second aim was to compare between the using three methods (methods of hot water, ethanol and methanol) with the antioxidant and reactive oxygen scavenging capacity results obtained.

\section{MeTHODS}

\subsection{Chemicals and leaf samples}

Potassium persulfate, 2,2'-Azinobis (3-ethylbenzothiazoline-6-sulphonic acid) diammonium salt (ABTS), trolox, ferric cloride, 2,4,6-tripyridyltriazine (TPTZ) and other chemicals were obtained from Sigma-Aldrich. Fifteen leaf samples were bought in a local supermarket (Center, Yozgat, Turkey).

\subsection{Method of ethanol}

$10 \mathrm{~g}$ of dried leaf sample were extracted with $70 \mathrm{ml}$ of ethanol for 2 times at $25{ }^{\circ} \mathrm{C}$ for one hour. Then the extracts were filtered by filter paper. After this step, the residues were reextracted with $60 \mathrm{ml}$ ethanol at $25{ }^{\circ} \mathrm{C}$ overnight and filtrates were intensified with a rotary evaporator. Then they were dried and weighed to specify the yield.

\subsection{Method of hot water}

To give fraction I, dried samples $(4 \mathrm{~g})$ were extracted with distilled water $(40 \mathrm{ml})$ at a temperature from 80 to $105{ }^{\circ} \mathrm{C}$ for $20 \mathrm{~min}$. To give fraction II, the residues were extracted with distilled water (60 $\mathrm{ml}$ ) at a temperature from 100 to $130{ }^{\circ} \mathrm{C}$ for $30 \mathrm{~min}$. After cooling to $25^{\circ} \mathrm{C}$, both of fractions were filtered. They were combined and dried at $40{ }^{\circ} \mathrm{C}$ and weighed to detect the yield [34].

\subsection{Method of methanol}

Dried sample $(10 \mathrm{~g})$ were extracted twice with methanol $(70 \mathrm{ml})$ at $25{ }^{\circ} \mathrm{C}$ for one hour. Then the extracts were filtered by filter paper. After this step, the residues were extracted again with methanol $(60 \mathrm{ml})$ at $25^{\circ} \mathrm{C}$ one night. Filtrates were intensified with an evaporator and then they were dried and weighed to detect the yield [35,36].

\subsection{FRAP assay}

The antioxidant capacity of samples was detected by Benzie and Strain's FRAP assay [25]. This assay evaluates the alteration in absorbance at $593 \mathrm{~nm}$ because of the generation of $\mathrm{Fe}^{\mathrm{II}}$-tripyridyltriazine from oxidised $\mathrm{Fe}^{\mathrm{III}}$. The reagent was made ready via mixing acetate buffer $(300 \mathrm{mmol} / \mathrm{L})$ with $2,4,6-$ tripyridyl-s-triazine $(10 \mathrm{mmol} / \mathrm{L})$ in $\mathrm{HCl}(40 \mathrm{mmol} / \mathrm{L})$ and with ferric chloride $(20 \mathrm{mmol} / \mathrm{L})$. As the 
standard, trolox was used. 6 repetitions for each extract were done. Samples were quantified by a spectrophotometer (Shimadzu UV-1800).

\subsection{TEAC assay}

TEAC assay is consisted in the reducing of the absorbance of the $\mathrm{ABTS}^{+}{ }^{+}[28]$ at 660,734 and 820 $\mathrm{nm}$. $\mathrm{ABTS}^{++}$was prepared by reacting ABTS solution with potassium persulfate $(2.45 \mathrm{mM})$. ABTS ${ }^{+}$ solution was diluted with phosphate buffer for obtaining an absorbance of $0.7 \pm 0.02$ at $734 \mathrm{~nm}$. Diluted $\mathrm{ABTS}^{+}$was added to trolox standard or biological sample, then this admixture was incubated for $6 \mathrm{~min}$. After this step, at $734 \mathrm{~nm}$, the inhibition in absorbance was evaluated. All evaluations were performed in 6 repetitions. Samples were quantified by a spectrophotometer (Shimadzu UV-1800).

\subsection{Determination of total phenolic content}

Total phenolic content was measured by the Singleton and Rossi's [37] method. Briefly, leaf extracts prepared (ethanol, methanol and hot water). After this step, Folin-Ciocalteu's phenol reagent and 7\% sodium carbonate were added to extracts then incubated for $8 \mathrm{~min} .2 \mathrm{~h}$ later, the absorbance was measured by a spectrophotometer (Shimadzu UV-1800) at $750 \mathrm{~nm}$. The standard was gallic acid. Samples were replicated six times. The results were expressed as $\mu \mathrm{g} \mathrm{GAE} / \mathrm{g}$ fw.

\subsection{Determination of total monomeric anthocyanins}

Total monomeric anthocyanins were measured via a $\mathrm{pH}$ differential procedure [38] by a spectrophotometer (Shimadzu UV-1800). At pH 1.0 and 4.5, absorbances were determined at 700 and $533 \mathrm{~nm}$ in buffers. Samples were replicated six times. Data were expressed as $\mu \mathrm{g}$ cy-3-glu/g fw.

\subsection{Determination of hydroxyl radical scavenging capacity}

Hydroxyl radical scavenging capacity was assessed by detected the ability of leaf sample extracts to reduce the generation of 2-hydroxyterephthalate which is a strongly fluorescent in a reaction between terephthalic acid and hydroxyl radical [39]. The mixture $(2.5 \mathrm{~mL})$ comprised TPA $(500 \mu \mathrm{M})$, EDTA $(10 \mu \mathrm{M}), \mathrm{FeSO}_{4}(10 \mu \mathrm{M})$, ascorbate $(100 \mu \mathrm{M})$ and $\mathrm{H}_{2} \mathrm{O}_{2}(100 \mu \mathrm{M})$ in a Na-phosphate buffer $(50 \mathrm{mM}$, $\mathrm{pH}$ 7.2). The procedure was calibrated with ethanol and hydroxyl radical scavenging capacities were given as $\mathrm{mM}$ ethanol equivalent/ $\mathrm{mL}$ leaf extract.

\subsection{Determination of superoxide scavenging capacity}

Superoxide scavenging capacity was determined as the superoxide radical inhibition caused decreasing of nitro blue tetrazolium to formazan [40]. Formazan formation was assessed at $560 \mathrm{~nm}$. The mixture $(1.0 \mathrm{~mL})$ consisted xanthine oxidase $(0.015 \mathrm{U})$ in Na-phosphate buffer $(50 \mathrm{mM}, \mathrm{pH} 7.2)$ comprising EDTA $(0.3 \mathrm{mM})$, xanthine $(0.2 \mathrm{mM})$ and nitro blue tetrazolium $(1 \mathrm{mg} / \mathrm{mL})$. Results were expressed as SOD unit equivalent $/ \mathrm{mL}$ leaf extract.

\subsection{Statistics}

Analyzing of the data were done by Tukey and one-way analysis of variance tests for comparison of all experimental goups by 20.0 version of SPSS program (significant at $\mathrm{P}<0.05$ ). The results were expressed as mean $\pm \mathrm{SD}$. Dependence of data sets was characterized by calculating their correlation coefficients. The correlation coefficient is between -1 and +1 specifing the degree of linear dependence between the variables right along with the positive or negative nature of dependence. between the variables, The closer the coefficient is to either -1 or +1 the stronger the correlation.

\section{ReSUlts}

Table 1. Correlation coefficients $\left(R_{P}\right)$ of different parameter sets measured in 15 leafs (for hot water method). TEAC, Trolox equivalent antioxidant capacity; FRAP, ferric reducing antioxidant power; Phen, total phenolics; $T M A$, total monomeric anthocyanins $\cdot O H$, hydroxyl radical scavenging capacity; SOS, superoxide scavenging capacity. $R_{P}>0,9$ values are in bold, 0,9> $R_{P}>0,8$ values are in bold italics.

\begin{tabular}{|c|c|c|c|c|c|c|}
\hline & TEAC & FRAP & Phen & TMA & $\cdot$ OH & SOS \\
\hline TEAC & 1 & $\mathbf{0 , 9 1 2}^{\mathbf{a}}$ & $\mathbf{0 , 8 5 1}^{\boldsymbol{a}}$ & 0,603 & 0,347 & 0,373 \\
\hline FRAP & & 1 & ${\mathbf{0 , 8 4 4 ^ { \boldsymbol { a } }}}$ & 0,611 & 0,361 & 0,388 \\
\hline Phen & & & 1 & 0,409 & 0,362 & 0,397 \\
\hline TMA & & & & 1 & 0,316 & 0,331 \\
\hline -OH & & & & & 1 & $\mathbf{0 , 8 2 5}^{\boldsymbol{a}}$ \\
\hline SOS & & & & & & 1 \\
\hline
\end{tabular}

a Significant correlation at $\mathrm{p}<0.05$. 
The Comparision of Antioxidant and Reactive Oxygen Scavenging Capacities of Ethanol, Methanol and Aqueous Extracts of Various Natural Leafs

The antioxidant capacities of 15 leaf extracts were evaluated with TEAC and FRAP assay. The results varied according to the assay used. Also we evaluated total phenolic content, total monomeric anthocyanins, hydroxyl radical scavenging capacity, superoxide scavenging capacity, too. Correlation coefficients $\left(\mathrm{R}_{\mathrm{P}}\right)$ of parameters which were examined in this study, were given in Table 1 .

\subsection{FRAP and TEAC assay results}

According to the FRAP and TEAC assays, S. nigra showed significantly lower and M. communis showed significantly higher antioxidant capacity than all other tested compounds for methods of ethanol, methanol and also hot water. Also, FRAP and TEAC values were in the order: Ethanol extract $<$ Methanol extract $<$ Hot water extract (Figures 1 and 2).
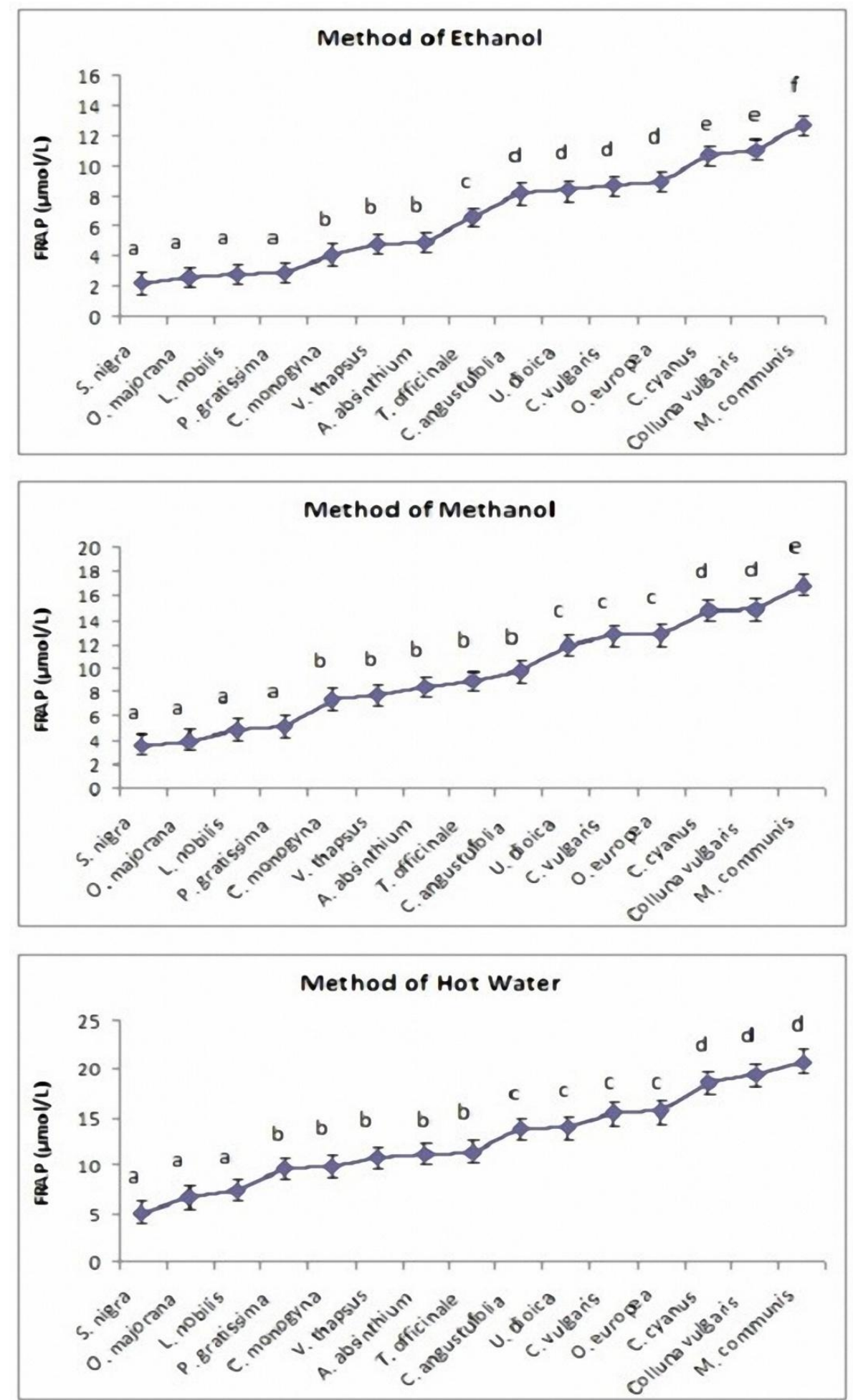

Figure 1. Antioxidant activity of 15 extract obtained using FRAP in vitro assay for the method of ethanol, methanol and hot water. Superscripts with different letters are significantly different. Significance at $P<0.05$. 
The Comparision of Antioxidant and Reactive Oxygen Scavenging Capacities of Ethanol, Methanol and Aqueous Extracts of Various Natural Leafs
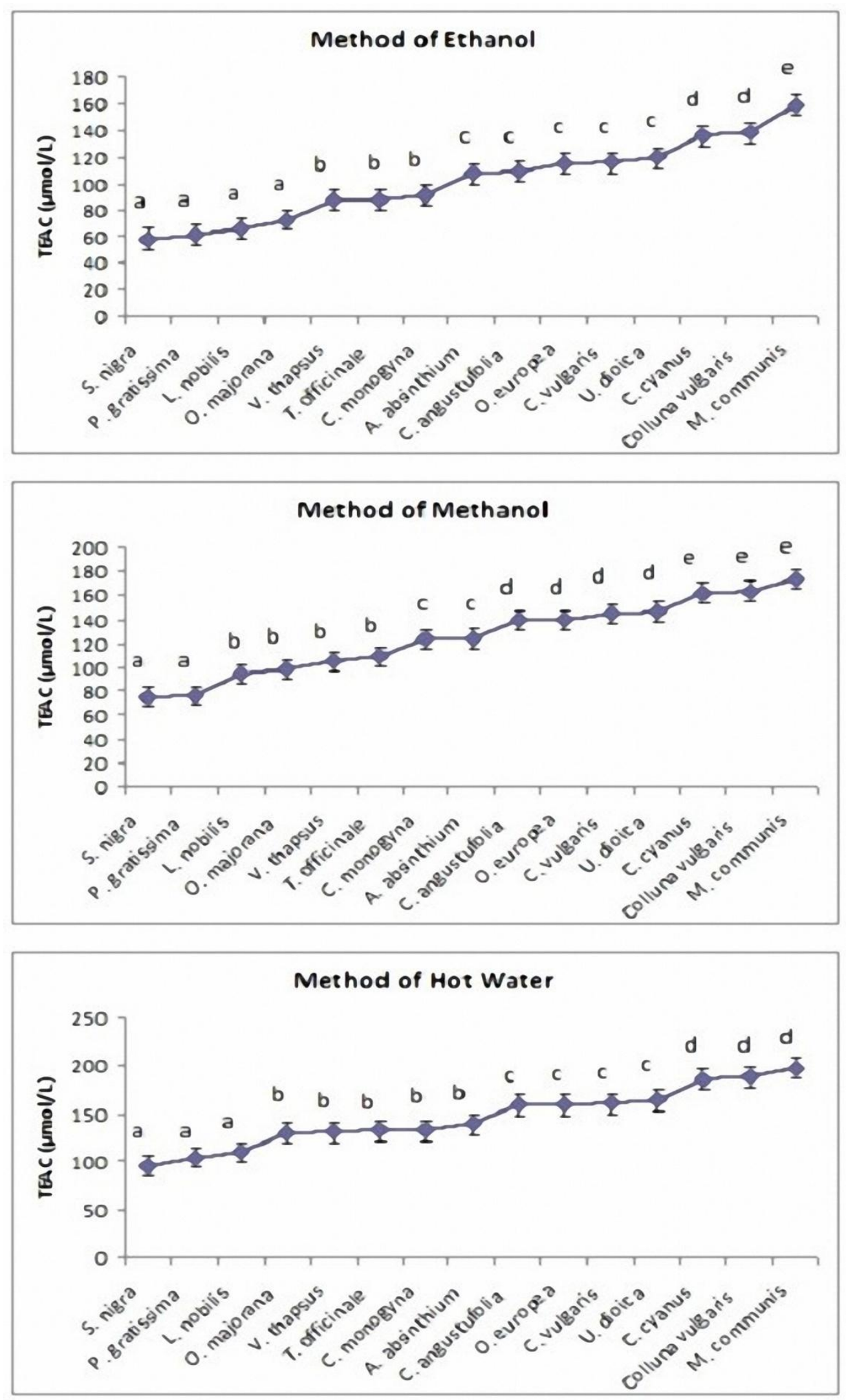

Figure 2. Antioxidant activities of 15 extract obtained using TEAC in vitro assay for the method of ethanol, methanol and hot water. Superscripts with different letters are significantly different. Significance at $P<0.05$.

\subsection{Results of Total Phenolic Content and Total Monomeric Anthocyanins}

M. communis (for ethanol: $2737 \pm 104,6$, for methanol: $2807,3 \pm 56,2$, for hot water: $2886,5 \pm 68,1$ ) had

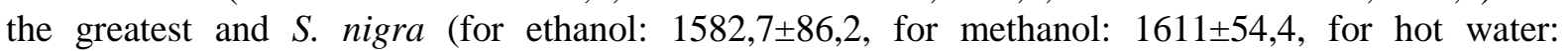


The Comparision of Antioxidant and Reactive Oxygen Scavenging Capacities of Ethanol, Methanol and Aqueous Extracts of Various Natural Leafs

$1698,1 \pm 55,3)$ had the lowest averages of total phenolic content for methods of ethanol, methanol and also hot water (Table 2).

M. communis (for ethanol: 507,8 $\pm 25,6$, for methanol: $531,2 \pm 59,5$, for hot water: $563,9 \pm 58,4$ ) had the greatest and S. nigra (for ethanol: $303,5 \pm 17,1$, for methanol: $309,7 \pm 16,8$, for hot water: $320,4 \pm 22,3$ ) had the lowest averages of total monomeric anthocyanins for methods of ethanol, methanol and also hot water (Table 3).

Total phenolic content and total monomeric anthocyanins values were in the order: Ethanol extract < Methanol extract $<$ Hot water extract (Tables 2 and 3).

Table 2. Total phenolic content of 15 leaf extracts ( $\mu \mathrm{g} G A E / g$ fw).

\begin{tabular}{|c|c|c|c|}
\hline & Method of Ethanol & Method of Methanol & Method of Hot Water \\
\hline S. nigra & $1582,7 \pm 86,2$ & $1611 \pm 54,4$ & $1698,1 \pm 55,3$ \\
\hline O. majorana & $1434,3 \pm 32,4$ & $1667,3 \pm 61,7$ & $1703,4 \pm 72,2$ \\
\hline L. nobilis & $1596,3 \pm 63,8$ & $1714,4 \pm 82,6$ & $1789,5 \pm 38,6$ \\
\hline P. gratissima & $1722 \pm 76,9$ & $1807,4 \pm 54,2$ & $1924,8 \pm 64,1$ \\
\hline C. monogyna & $1686,5 \pm 81,4$ & $1862,7 \pm 62,3$ & $1945,5 \pm 88,7$ \\
\hline V. thapsus & $1984,4 \pm 57,6$ & $2044,8 \pm 59,1$ & $2187 \pm 74,9$ \\
\hline A. absinthium & $2088,6 \pm 89,4$ & $2201,7 \pm 45,8$ & $2294,6 \pm 66,3$ \\
\hline T. officinale & $1899,3 \pm 81,2$ & $2195,8 \pm 67,2$ & $2474, \pm 85,9$ \\
\hline C. angustufolia & $2195,7 \pm 38,5$ & $2259,6 \pm 84,1$ & $2499,5 \pm 91,2$ \\
\hline U. dioica & $2156,1 \pm 66,4$ & $2351,8 \pm 74,3$ & $2564,4 \pm 59,7$ \\
\hline C. vulgaris & $2355,8 \pm 64,5$ & $2397,1 \pm 82,6$ & $2686,5 \pm 58,6$ \\
\hline O. europea & $2542 \pm 101,2$ & $2604,9 \pm 55,3$ & $2784,8 \pm 39,5$ \\
\hline C. cyanus & $2556,1 \pm 51,8$ & $2688,2 \pm 67,9$ & $2799,1 \pm 84,8$ \\
\hline Colluna vulgaris & $2627,4 \pm 55,7$ & $2681,9 \pm 82,6$ & $2886,5 \pm 68,1$ \\
\hline M. communis & $2737 \pm 104,6$ & $2807,3 \pm 56,2$ & \\
\hline
\end{tabular}

Values represent mean \pm S.D. calculated from six replicates.

Table 3. Total monomeric anthocyanins of 15 leaf extracts ( $\mu$ g cy-3-glu/g fw).

\begin{tabular}{|c|c|c|c|}
\hline & Method of Ethanol & Method of Methanol & Method of Hot Water \\
\hline S. nigra & $303,5 \pm 17,1$ & $309,7 \pm 16,8$ & $320,4 \pm 22,3$ \\
\hline O. majorana & $302,4 \pm 21,8$ & $307,9 \pm 34,2$ & $331,7 \pm 19,5$ \\
\hline L. nobilis & $313,2 \pm 33,7$ & $336,5 \pm 44,6$ & $362,1 \pm 24,8$ \\
\hline P. gratissima & $315,2 \pm 42,1$ & $332,2 \pm 14,7$ & $362,6 \pm 51,4$ \\
\hline C. monogyna & $355,8 \pm 31,5$ & $369,2 \pm 42,3$ & $376,3 \pm 21,9$ \\
\hline V. thapsus & $351,2 \pm 51,3$ & $374,6 \pm 22,7$ & $394,4 \pm 28,1$ \\
\hline A. absinthium & $346,4 \pm 35,3$ & $360,8 \pm 47,5$ & $392,1 \pm 58,2$ \\
\hline T. officinale & $352,9 \pm 48,7$ & $376,3 \pm 42,4$ & $404,5 \pm 64,9$ \\
\hline . angustufolia & $345,8 \pm 19,6$ & $372,1 \pm 55,3$ & $407,8 \pm 57,1$ \\
\hline U. dioica & $408,2 \pm 46,4$ & $424,7 \pm 28,6$ & $460,9 \pm 55,6$ \\
\hline C. vulgaris & $416,9 \pm 35,2$ & $440,5 \pm 66,1$ & $476,8 \pm 61,5$ \\
\hline O. europea & $457,7 \pm 45,3$ & $487,9 \pm 50,4$ & $507,2 \pm 51,3$ \\
\hline C. cyanus & $450,3 \pm 38,6$ & $471,2 \pm 59,7$ & $510,6 \pm 39,1$ \\
\hline Colluna vulgaris & $445 \pm 44,1$ & $469,7 \pm 32,3$ & $515,5 \pm 71,4$ \\
\hline M. communis & $467,8 \pm 25,6$ & $491,2 \pm 59,5$ & $533,9 \pm 58,4$ \\
\hline
\end{tabular}

Values represent mean \pm S.D. calculated from six replicates.

\subsection{Results of Hydroxyl Radical and Superoxide Scavenging Capacities}

M. communis (for ethanol: 21,9 $\pm 5,2$, for methanol: $23,5 \pm 3,3$, for hot water: $26 \pm 6,4$ ) had the greatest and S. nigra (for ethanol: 15,2 $\pm 1,1$, for methanol: $15,7 \pm 1,8$, for hot water: $16,5 \pm 2,4$ ) had the lowest averages of hydroxyl radical capacity for methods of ethanol, methanol and also hot water (Table 4).

M. communis (for ethanol: $25,5 \pm 4,3$, for methanol: $28,7 \pm 6,4$, for hot water: $30,5 \pm 6,7$ ) had the greatest and S. nigra (for ethanol: 10,2 $\pm 2,4$, for methanol: $12,5 \pm 3,7$, for hot water: $13,9 \pm 3,4$ ) had the lowest averages of superoxide scavenging capacity for methods of ethanol, methanol and also hot water (Table 5).

Hydroxyl radical and superoxide scavenging capacity values were in the order: Ethanol extract < Methanol extract < Hot water extract (Tables 4 and 5). 
The Comparision of Antioxidant and Reactive Oxygen Scavenging Capacities of Ethanol, Methanol and Aqueous Extracts of Various Natural Leafs

Table 4. Hydroxyl radical scavenging capacity of 15 leaf extracts ( $\mathrm{mM} \mathrm{EtOH/mL)}$

\begin{tabular}{|c|c|c|c|}
\hline & Method of Ethanol & Method of Methanol & Method of Hot Water \\
\hline S. nigra & $15,2 \pm 1,1$ & $15,7 \pm 1,8$ & $16,5 \pm 2,4$ \\
\hline O. majorana & $14,3 \pm 2,4$ & $14,9 \pm 2,6$ & $15,4 \pm 3,1$ \\
\hline L. nobilis & $15,8 \pm 3,6$ & $16,1 \pm 1,9$ & $16,6 \pm 2,2$ \\
\hline . gratissima & $12,2 \pm 3,4$ & $12,8 \pm 2,7$ & $13,5 \pm 4,2$ \\
\hline C. monogyna & $14,8 \pm 4,3$ & $16,1 \pm 3,8$ & $17,4 \pm 2,6$ \\
\hline V. thapsus & $17,3 \pm 4,1$ & $17,4 \pm 4,3$ & $17,6 \pm 3,4$ \\
\hline A. absinthium & $14,5 \pm 5,2$ & $15,1 \pm 2,4$ & $15,5 \pm 5,2$ \\
\hline T. officinale & $17,9 \pm 4,7$ & $18,6 \pm 3,1$ & $18,9 \pm 4,5$ \\
\hline C. angustufolia & $14,5 \pm 4,8$ & $15,4 \pm 2,6$ & $15,5 \pm 4,2$ \\
\hline U. dioica & $18,6 \pm 5,6$ & $19 \pm 5,1$ & $19,4 \pm 3,9$ \\
\hline C. vulgaris & $13,6 \pm 4,4$ & $13,8 \pm 3,7$ & $14,3 \pm 4,6$ \\
\hline O. europea & $15,8 \pm 4,9$ & $16,4 \pm 5,8$ & $21,1 \pm 5,5$ \\
\hline C. cyanus & $19,4 \pm 5,2$ & $19,8 \pm 4$ & $19,2 \pm 3,7$ \\
\hline Colluna vulgaris & $17,5 \pm 6,3$ & $18,7 \pm 4,2$ & $26 \pm 6,4$ \\
\hline M. communis & $21,9 \pm 5,2$ & $23,5 \pm 3,3$ & \\
\hline
\end{tabular}

Values represent mean \pm S.D. calculated from six replicates.

Table 5. Superoxide scavenging capacity of 15 leaf extracts (unit SOD/mL)

\begin{tabular}{|c|c|c|c|}
\hline & Method of Ethanol & Method of Methanol & Method of Hot Water \\
\hline S. nigra & $10,2 \pm 2,4$ & $12,5 \pm 3,7$ & $13,9 \pm 3,4$ \\
\hline O. majorana & $12,6 \pm 4,1$ & $13,4 \pm 3,1$ & $14,7 \pm 4,6$ \\
\hline L. nobilis & $13,4 \pm 3,8$ & $14,6 \pm 4,2$ & $15,4 \pm 3,5$ \\
\hline $\boldsymbol{P}$ gratissima & $11,6 \pm 5,2$ & $12,7 \pm 3,6$ & $14,8 \pm 4,8$ \\
\hline C. monogyna & $13,4 \pm 5,7$ & $15,6 \pm 4,5$ & $17,5 \pm 3,9$ \\
\hline V. thapsus & $16,9 \pm 4,5$ & $18,2 \pm 3,7$ & $20,1 \pm 6,1$ \\
\hline A. absinthium & $13,7 \pm 5,3$ & $14,2 \pm 4,8$ & $18,6 \pm 3,3$ \\
\hline T. officinale & $17,2 \pm 4,6$ & $20,3 \pm 5,1$ & $22,9 \pm 5,2$ \\
\hline C. angustufolia & $14,4 \pm 5,4$ & $18,3 \pm 6,5$ & $21,2 \pm 3,1$ \\
\hline U. dioica & $18,1 \pm 6$ & $22,7 \pm 5,5$ & $26 \pm 6,7$ \\
\hline C. vulgaris & $17,5 \pm 4,7$ & $18,7 \pm 6,4$ & $20,8 \pm 4,6$ \\
\hline O. europea & $20,4 \pm 3,6$ & $22,5 \pm 2,2$ & $26,2 \pm 4,3$ \\
\hline C. cyanus & $20,8 \pm 5,9$ & $22,9 \pm 3,1$ & $24,8 \pm 6,2$ \\
\hline Colluna vulgaris & $18,9 \pm 6,1$ & $21,6 \pm 3,3$ & $30,5 \pm 6,7$ \\
\hline M. communis & $25,5 \pm 4,3$ & $28,7 \pm 6,4$ & \\
\hline
\end{tabular}

Values represent mean \pm S.D. calculated from six replicates.

\section{Discussion}

Plants are important source of natural products which show an alteration largely in terms of biological properties and structure [41]. In latest years, the protection from cardiovascular diseases and cancer has been related to the diet with teas, vegetables or fresh fruits which were rich in antioxidants $[42,43]$. Feed with herbs in the herbal teas is the most popular form of herbs among people in the world [15].

Methods which determine the combined antioxidant impact of the nonenzymatic defense sysyem can be helpful in suppling an index of ability to withstand oxidative stress [25]. The evaluated antioxidant ability of a sample hinges on which free radical producer and which technology or oxidant is used in the evaluation. For this reason, comparing of varied analytical tests is useful for better interpretation and understanding of the data [33].

It is thereby essential to set up proper procedures to measure the efficacy of the antioxidant capacities of the extracted and prepared compounds correctly [44]. Traditional procedures for mesuring antioxidant ability are usually divided into 2 types: direct measurement and measurement of the level of the essential components that have antioxidant activity. In the first type of procedure, FRAP and TEAC are the most largely used procedures [45]. In the second type of procedure, analytical tests such as high performance capillary electrophoresis, colorimetric determination and high performance liquid chromatography have been used mostly [32]. Recently, it has been demonstrated that the TEAC assay may be used for antioxidant activity mensuration of brain homogenates [46]. Similarly, the 
FRAP assay was latterly utilised to detect lettuce tissue's antioxidant capacity [47]. We choosed the TEAC and FRAP assays to determine the antioxidant ability of the 15 leafs. These assays utilise different technology for detecting antioxidant ability and we must kept this truth in mind when commenting the achieved data. Both these tests are rapid and don't need advanced instrument which make them appropriate for evaluations of samples [33]. FRAP and TEAC assays were applied to examine total antioxidant ability in tobacco leafs [6], Morus nigra and Morus rubra fruits [48], Zea mays [49]. Both by FRAP and TEAC assay, we observed that $M$. communis had the greatest and $S$. nigra had the lowest total antioxidant capacity. FRAP and TEAC values which we obtained in this study, support each other. FRAP and TEAC values had strong positive correlation $\left(\mathrm{R}_{\mathrm{P}}\right.$ : 0,912). Similarly, in a previous study different total antioxidant capacity measurements gave very similar data for spice samples, too [50].

Comparing of various analytical procedures is useful for better commentary and understanding of the data on the antioxidant ability of samples [33]. Therefore, total phenolic content and total monomeric anthocyanins and also hydroxyl radical and superoxide scavenging capacities were determined in this study additively FRAP and TEAC assays.

A lot of evidences indicate that contents of phenolics and anthocyanins of leafs, fruits and vegetables may provide health advantages like as decreased risk of cardiovascular disease and cancers $[48,51]$. Among the leafs examined in this work, M. communis had the highest averages of total phenolic content and total monomeric anthocyanins and $S$. nigra had the least averages of total phenolic content and total monomeric anthocyanins. Total phenolic content of $S$. nigra had 41,81\%, 42,61\%, $41,17 \%$ less total phenolic content than $M$. communis for ethanol, methanol and hot water extracts, respectively. Similar patterns were observed for total monomeric anthocyanins. S. nigra had 35,12\%, 36,95\%, 39,99\% less than $M$. communis for ethanol, methanol and hot water extracts, respectively. İncreasing in FRAP and TEAC values in $M$. communis leafs which reported in this paper may be due to the increasing of total phenolic contents. Because, total phenolic contents and FRAP and TEAC values had strong positive correlation $\left(\mathrm{R}_{\mathrm{P}}: 0,844\right.$ and $\mathrm{R}_{\mathrm{P}}$ : 0,851, respectively). Similar with our results, Özgen et al. [48] found in their study that increaesing in phenolic contents observed with increasing in FRAP and TEAC assay values. Majer et al. [6] observed that FRAP and TEAC values enhenced with increasing in total phenolic content. Yang and Zhai ${ }^{[49]}$ demonstrated that increaesing anthocyanin contents observed with increasing in FRAP and TEAC assay values, too. But in our study total anthocyanin contents and FRAP and TEAC values had weak positive correlation $\left(R_{P}: 0,611\right.$ and $R_{P}$ : 0,603 , respectively).

Previously, several authors have indicated that phenolics and anthocyanins have significant freeradical scavenging and antioxidant capacities [48,52]. For evaluating free-radical scavenging activities, hydroxyl radical and superoxide scavenging capacities were studied in this work. There are studies that investigated these two parameters for supporting total antioxidant capacity data [6,53]. $M$. communis leafs had the greatest and S. nigra leafs had the least hydroxyl radical and superoxide scavenging abilities. Hydroxyl radical scavenging capacity of M. communis had 30,59\%, 33,19\%, $36,54 \%$ greater than $S$. nigra for ethanol, methanol and hot water extracts, respectively. Superoxide radical scavenging capacity of $M$. communis had $60 \%, 56,45 \%, 54,43 \%$ greater than $S$. nigra for ethanol, methanol and hot water extracts, respectively. In this work hydroxyl radical and superoxide scavenging capacity and FRAP and TEAC values had no correlation. Parallel with this study, Majer et al. [6] determined that the two parameters of antioxidant capacity (FRAP and TEAC) selected for their study weren't correlated to superoxide or hydroxyl radical scavenging. Furthermore, none of the other examined antioxidant contents (total phenolics, anthocyanins) were indicative of ROS scavenging ability. A deprivation of correlation between TEAC values and hydroxyl radical scavenging capacity has already been reported [53]. These data indicate that ROS scavenging capacities of leafs can be measured directly, but these parameters cann't be concluded from other antioxidant capacities.

Extraction method types effect the extraction yield and antioxidant capacity of leaf extracts. Some previous works about the extraction methods of antioxidant compounds from leafs have been notified [18]. However there isn't any comparable work on the several extraction method effect about the antioxidant capacity of 15 leafs which we used in this work. Antioxidant ability of leafs of hot water 
method was the higher than two other methods for FRAP and TEAC assays also total phenolic content and total monomeric anthocyanins and hydroxyl radical and superoxide scavenging capacities. The method which have at least activity was the method of ethanol for FRAP and TEAC assays. Water extract had more total antioxidant capacity in Yang and Kang's work [54] compared with ethanol extract in a previous study. Enhanced total antioxidant capacity with water extract were reported also by [18] compared with methanol and ethyl acetate extracts.

\section{CONCLUSION}

As far as we concerned and from the inspected literature, this is first study that the total antioxidant capacity, total monomeric anthocyanins, total phenolic content, hydroxyl radical and superoxide scavenging capacities of 15 extract has been reported. 15 leaf extracts have a considerable amount of antioxidant capacity and may be rich sources of antioxidant compounds. All parameters of water extracts of the 15 leafs showed higher antioxidant activity than ethanol and methanol extracts. According to our study for both of FRAP and TEAC assays, also total monomeric anthocyanins, total phenolic content, hydroxyl radical and superoxide scavenging capacities as seen in the all figures and tables the most active herb was M. comminis and the least active herb was S. nigra. Further work will be carried out to find biologically active compounds in these leafs.

\section{Competing interests}

The authors declare that they have no competing interests.

\section{REFERENCES}

[1] Fang YZ., Yang S., Wu GY., Free radicals, antioxidants and nutrition, Nutrition. 18, 872-879 (2002).

[2] Guo C., Yang J., Wei J., Li Y., Xu J., Jiang Y., Antioxidant activities of peel, pulp and seed fractions of common fruits as determined by FRAP assay, Nutr. Res. 23, 1719-1726 (2003).

[3] Jacob RA., The integrated antioxidant system, Nutr. Res. 15, 755-766 (1995).

[4] Apel K., Hirt H., Reactive oxygen species: Metabolism, oxidative stress, and signal transduction, Annu. Rev. Plant. Biol. 55, 373-399 (2004).

[5] Asada K., Production and scavenging of reactive oxygen species in chloroplasts and their functions, Plant Physiol. 141, 391-396 (2006).

[6] Majer P., Stoyanova S., Hideg E., Do leaf total antioxidant capacities (TAC) reflect specific antioxidant potentials? - A comparison of TAC and reactive oxygen scavenging in tobacco leaf extracts, J. Photochem. Photobiol. B. 100, 38-43 (2010).

[7] Gliszczynska-Swiglo A., Antioxidant activity of water soluble vitamins in the TEAC (trolox equivalent antioxidant capacity) and the FRAP (ferric reducing antioxidant power) assays, Food Chem. 96, 131-136 (2006).

[8] Valko M., Leibfritz D., Moncol J., Cronin MT., Mazur M., Telser J., Free radicals and antioxidants in normal physiological functions and human disease, I. J. B. C. B. 39, 44-84 (2007).

[9] Wootton-Beard PC., Moran A., Ryan L., Stability of the total antioxidant capacity and total polyphenol content of 23 commercially available vegetable juices before and after in vitro digestion measured by FRAP, DPPH, ABTS and Folin-Ciocalteu methods, Food Res. Int. 44, 217-224 (2011).

[10] Renaud SC., Gueguen R., Schenker J., D'Houtaud A., Alcohol and mortality in middle-aged men from eastern France, Epidemiol. 9, 184-188 (1998).

[11] Temple NJ., Antioxidants and disease: more questions than answers, Nutr. Res. 20, 449-459 (2000).

[12] Thaipong K., Boonprakob U., Crosby K., Cisneros-Zevallos L., Byrne DH., Comparison of ABTS, DPPH, FRAP, and ORAC assays for estimating antioxidant activity from guava fruit extracts, J. Food Compos. Anal. 19, 669-675 (2006).

[13] Warren CP., Antioxidant effects of herbs. Lancet. 353, 676-676 (1999).

[14] Ng TB., Liu F., Wang ZT., Antioxidative activity of natural products from plants, Life Sci. 66, 709-723 (2000). 
[15] Speisky H., Rocco C., Carrasco C., Lissi EA., Lopez-Alarcon C., Antioxidant screening of medicinal herbal teas, Phytother. Res. 20, $462-467$ (2006).

[16] Salah N., Miller NJ., Parganga G., Tifburg L., Bolwell GP., Ice-Evan C., Polyphenolic flavonols as scavengers of aqueous phase radicals and as chain-breaking antioxidants, Arch. Biochem. Biophys. 322, 339-346 (1995).

[17] Tanizawa H., Toda S., Sazuka T., Taniyama T., Hayashi T., Arichi S., Takino Y., Natural antioxidants. I. antioxidative components of tea leaf (Thea sinensis L.), Chem. Pharm. Bull. 32, 2011-2014 (1984).

[18] Farhoosh R., Golmovahhed GA., Khodaparast MHH., Antioxidant activity of various extracts of old tea leaves and black tea wastes (Camellia sinensis L.), Food Chem. 100, 231-236 (2007).

[19] Shahidi F., Wanasundara PD., Phenolic antioxidants, Crit. Rev. Food Sci. Nutr. 32, 67-103 (1992).

[20] Tijburg LBM., Mattern T., Folts JD., Weisgerber UM., Katan MB., Tea flavanoids and cardiovascular diseases: a review, Crit. Rev. Food Sci. Nutr. 37, 771-785 (1997).

[21] Wiseman SA., Balentine DA., Frei B., Antioxidants in tea, Crit. Rev. Food Sci. Nutr. 37, 705718 (1997).

[22] Çelik H., Özgen M., Serçe S., Kaya C., Phytochemical accumulation and antioxidant capacity at four maturity stages of cranberry fruit, Sci. Hortic. 117, 345-348 (2008).

[23] Özgen M., Serçe S., Gunduz K., Yen F., Kafkas E., Paydas S., Determining total phenolics and antioxidant capacities of selected Fragaria genotype, Asian J. Chem. 19, 5573-5581 (2007).

[24] Sun J., Chu YF., Wu X., Liu RH., Antioxidant and antiproliferative activities of common fruits, J. Agric. Food Chem. 50, 7449-7454 (2002).

[25] Benzie IFF., Strain JJ., The ferric reducing ability of plasma (FRAP) as a measure of antioxidant power: the FRAP assay, Anal. Biochem. 239, 70-76 (1996).

[26] Benzie IFF., Strain JJ., Ferric reducing/antioxidant power assay: direct measure of total antioxidant activity of biological fluids and modified version for simultaneous measurement of total antioxidant power and ascorbic acid concentration, Methods Enzymol. 299, 15-27 (1999).

[27] Griffin SP., Bhagooli R., Measuring antioxidant potential in corals using the FRAP assay, J. Exp. Mar. Biol. Ecol. 302, 201-211 (2004).

[28] Re R., Pellegrini N., Proteggente A., Pannala A., Yang M., Rice-Evans C., Antioxidant activity applying an improved ABTS radical cation decolourisation assay, Free Radical Biol. Med. 26, 1231-1237 (1999).

[29] Zulueta A., Esteve MJ., Frigola A., ORAC and TEAC assays comparison to measure the antioxidant capacity of food products, Food Chem. 114, 310-316 (2009).

[30] Huang D., Ou B., Prior RL., The chemistry behind antioxidant capacity assays, J. Agric. Food Chem. 53, 1841-1856 (2005).

[31] Serrano J., Gofli I., Saura-Calixto F., Food antioxidant capacity determined by chemical methods may underestimate the physiological antioxidant capacity, Food Res. Int. 40, 15-21 (2007).

[32] Wu D., Chen J., Lu B., Xiong L., He Y., Zhang Y., Application of near infrared spectroscopy for the rapid determination of antioxidant activity of bamboo leaf extract, Food Chem. 135, 21472156 (2012).

[33] Katalinic V., Modun D., Music I., Boban M., Gender differences in antioxidant capacity of rat tissues determined by 2,2V-azinobis (3-ethylbenzothiazoline 6-sulfonate; ABTS) and ferric reducing antioxidant power (FRAP) assays, Comp. Biochem. Physiol. 140, 47-52 (2005).

[34] Mai J., Chamber LJ., Mcdonald RE., Process for inhibiting lipid oxidation in food and composition thereby. United State Patents; 1990. pp. 681, 925.

[35] Sakanaka S., Tachibana Y., Okada Y., Preparation and antioxidant properties of extracts of Japanese persimmon leaf tea (kakinoha-cha), Food Chem. 89, 569-575 (2005).

[36] Zandi P., Gordon MH., Antioxidant activity of extracts from old tea leaves, Food Chem. 64, 285288 (1999).

[37] Singleton VL., Rossi JL., Colorimetry of total phenolics with phosphomolybdicphosphotungstic acid reagents, Am. J. Enol. Viticult. 16, 144-158 (1965). 
[38] Giusti MM., Wrolstad RE., Characterization and measurement of anthocyanins by UV-visible spectroscopy Unit F1.2. In: Wrolstad, R.E., Schwartz, S.J. (Eds.), Handbook of Food Analytical Chemistry, New York: Wiley; 2005. pp. 19-31.

[39] Halliwell B., Gutteridge JM., Free radicals in biology and medicine, $4^{\text {th }}$ ed., New York: Oxford University Press Inc; 2007.

[40] McCord JM., Fridovich I., Superoxide dismutase: an enzymic function for erythrocuprein (hemocuprein), J. Biol. Chem. 244, 6049-6055 (1969).

[41] Tadhani MB., Patel VH., Subhash R., In vitro antioxidant activities of Stevia rebaudiana leaves and callus, J. Food Compos. Anal. 20, 323-329 (2007).

[42] Johnson IT., Antioxidants and antitumour properties. Cambridge: Woodhead Publishing Ltd; 2001. pp. 100-123,

[43] Virgili F., Scaccini C., Packer L., Rimbach G., Cardiovascular disease and nutritional phenolics antioxidants in food. Cambridge: Woodhead Publishing Ltd; 2001. pp. 87-99.

[44] Liu ZQ., Chemical methods to evaluate antioxidant ability, Chem. Rev. 110, 5675-5691 (2010).

[45] Saura-Calixto F., Perez-Jimenez J., Arranz S., Tabernero M., Diaz-Rubio ME., Serrano J., Goni I., Updated methodology to determine antioxidant capacity in plant foods, oils and beverages: extraction, measurement and expression of results, Food Res. Int. 41, 274-285 (2008).

[46] Shea TB., Rogers E., Ashline D., Ortiz D., Sheu MS., Quantification of antioxidant activity in brain tissue homogenates using the dtotal equivalent antioxidant capacity, T. J. Neurosci. Methods. 125, 55-58 (2003).

[47] Kang HM., Saltveit ME., Antioxidant capacity of lettuce leaf tissue increases after wounding, J. Agric. Food Chem. 50, 7536-7541 (2002).

[48] Özgen M., Serçe S., Kaya C., Phytochemical and antioxidant properties of anthocyanin-rich Morus nigra and Morus rubra fruits. Sci. Hortic. 119, 275-279 (2009).

[49] Yang Z., Zhai W., Identification and antioxidant activity of anthocyanins extracted from the seed and cob of purple corn (Zea mays L.), Innov. Food Sci. Emerg. Technol. 11, 169-176 (2010).

[50] Hossain MB., Brunton NP., Barry-Ryan C., Martin-Diana AB., Wilkinson M., Antioxidant activity of spice extracts and phenolics in comparison to synthetic antioxidants, Rasayan J. Chem. 1, 751-756 (2008).

[51] Zafra-Stone S., Yasmin T., Bagchi M., Chatterjee A., Vinson JA., Bagchi D., Berry anthocyanins as novel antioxidants in human health and disease prevention, Mol. Nutr. Food Res. 51, 675-683 (2007).

[52] Stintzing FC., Carle R., Frei B., Wrolstad RE., Color and antioxidant properties of cyanidinbased anthocyanin pigments. Color and antioxidant properties of cyanidin-based anthocyanin pigments, J. Agric. Food Chem. 50, 6172-6180 (2002).

[53] Van den Berg R., Haenen GRMM., Van den Berg H., Van der Vijgh W., Bast A., The predictive value of the antioxidant capacity of structurally related flavonoids using the trolox equivalent antioxidant capacity (TEAC) assay, Food Chem. 70, 391-395 (2000).

[54] Yang XN., Kang SC., In vitro antioxidant activity of the water and ethanol extracts of Forsythia koreana flowers, Nat. Prod. Res. 26(4), 375-379 (2012). 